\title{
O PROGRAMA DE EDUCAÇÃO CONTINUADA (PEC) NA AVALIAÇÃO DE SEUS ALUNOS*
}

\section{Program PEC evaluated by student teachers}

\author{
Myriam Krasilchik ${ }^{1}$ \\ Marieta Lucia Machado Nicolau ${ }^{2}$ \\ Maria Catarina Cury ${ }^{3}$
}

\begin{abstract}
Resumo: O trabalho tem objetivo de apresentar uma análise dos dados de avaliação do Programa de Educação Continuada - Formação Universitária/Municípios PEC-USP, na perspectiva dos professores que o cursaram no período de 2003 a 2004. A primeira parte descreve o Programa em linhas gerais; a segunda, apresenta os procedimentos e a interpretação dos dados coletados na investigação realizada. Os resultados obtidos extrapolam o âmbito do curso e podem subsidiar programas de formação de professores em vários níveis e de diferentes disciplinas.
\end{abstract}

Palavras-chave: Avaliação. Formação de professores. Impacto de programa. Mudança.

\begin{abstract}
The objective of this paper is to analyze the evaluation data of PEC - Program of Continuous Education - University Graduation - from the perspective of student teachers of the program (period 2003-2004). The first part of the paper outlines the Program and the second part presents the methodology and interpretation of the data collected from the student teachers. The results can inform several courses for teacher preparation in different disciplines and at different school levels.
\end{abstract}

Key words: Evaluation. Teacher preparation. Program impact. Change.

\footnotetext{
*Agradecemos o auxílio e as inestimáveis sugestões dos especialistas da Fuvest, da professora doutora Valeria Arantes do Nascimento, da diretora da Biblioteca da FEUSP, Raimunda Miguelina Alves Flexa, e da equipe do PEC - USP.

${ }^{1}$ Licenciada em História Natural; doutora em Educação, professora emérita, Faculdade de Educação, Universidade de São Paulo (FEUSP); vice-coordenadora, PEC/USP. São Paulo, SP. <mkrasilc@usp.br>

${ }^{2}$ Doutora em Educação; diretora de Unidade, Faculdades Radial de Curitiba, PR.

<cury.catarina@uol.com.br>

3 Licenciada em Pedagogia; doutora em Educação; docente, FEUSP; coordenadora, PEC/USP. São Paulo, SP. $<$ mnicolau@usp.br>
}

\footnotetext{
1 Av. da Universidade, 308, sala 36, Cidade Universitária - São Paulo, SP 05.508-040
} 


\section{O PEC - Programa de Formação Continuada}

Durante os anos de 2003 e 2004, o PEC-USP - foi desenvolvido pela Universidade de São Paulo em convênio com a Pontifícia Universidade Católica de São Paulo (PUC-SP), com apoio das Prefeituras dos Municípios envolvidos, da FDE (Fundação Para o Desenvolvimento da Educação), da UNDIME (União Nacional dos Dirigentes Municipais de Educação), da Fundação Vanzolini e da Fundação de Apoio à Faculdade de Educação (FAFE). Tratou-se de um programa presencial, perfazendo uma carga horária de 3.344 horas, com forte apoio de mídias interativas, que buscou sistematizar os referenciais teóricos da Educação Infantil e do Ensino Fundamental - $1^{\mathrm{a}}$ a $4^{\mathrm{a}}$ séries, por meio de Temas e Unidades presentes na estrutura curricular desses segmentos da escolaridade. Todas as decisões referentes à organização e ao planejamento acadêmico das ações no âmbito do projeto foram tomadas pelas comissões das referidas universidades.

A produção do material didático utilizado ao longo do programa ficou a cargo da coordenação do PEC-USP - Universidade de São Paulo e PUC-SP. Estiveram sob responsabilidade da coordenação da USP sessenta grupos de alunos, distribuídos em 23 pólos (local físico onde as atividades ocorreram), em diferentes partes do estado de São Paulo.

Cada um dos grupos, constituídos por quarenta professores e professoras, esteve sob tutoria de um profissional da educação, que se responsabilizou por auxiliá-los, garantindo o bom andamento das atividades programadas, interagindo com os responsáveis pela instituição a que os pólos estavam ligados e reportando-se à coordenação central.

Além de tutores, outros profissionais, nomeados de orientadores e assistentes, auxiliaram os alunos durante o desenvolvimento de todo o programa. Aos orientadores coube atendêlos no desenvolvimento de trabalhos de pesquisa, na correção dos relatórios e provas e discussão dos conteúdos estudados; aos assistentes coube dar-lhes suporte para os trabalhos monitorados online. Para concatenar o conjunto diversificado das atividades e garantir a coesão e coerência do programa houve reuniões periódicas presenciais e comunicação à distância entre os responsáveis pelos alunos nos pólos e a coordenação central. Tais ações permitiram que os estudantes desenvolvessem um conjunto diversificado de atividades, do qual faziam parte os módulos integrados que sistematizaram os referenciais do programa nos temas e unidades que compõem a estrutura curricular do curso. Vale ressaltar que todas essas ações foram adequadas à formação em nível superior de docentes, em exercício, de Educação Infantil e dos anos iniciais do Ensino Fundamental.

O PEC-USP teve como referências os marcos da política educacional ditados pela Lei de Diretrizes e Bases da Educação Nacional (LDB) e pelas Diretrizes Curriculares Nacionais do Ensino Fundamental, as recomendações dos Parâmetros Curriculares Nacionais, do Referencial Curricular Nacional para a Educação Infantil e os dispositivos expedidos pelos Conselhos Nacional e Estadual de Educação relativos à formação de professores para a educação básica, articulados com os princípios e diretrizes da política educacional dos municípios participantes. O fundamento legal do PEC-USP é o Art. 81 da LDB: "É permitida a organização de programas ou instituições de ensino experimentais, desde que obedecidas as disposições desta lei” (BRASIL, 1996, p. 28).

Com a convicção de que os professores são elementos essenciais na implementação e no aperfeiçoamento das políticas educacionais, as atividades propostas ao longo do curso 
tiveram como pontos de partida as próprias experiências dos docentes como profissionais da educação. Buscou-se uma coerência entre a formação oferecida e a prática que desenvolvem nas instituições escolares. A população de professores, que, em sua maioria, tinha deixado a escola como aluno há bastante tempo, respondeu com surpreendente rapidez e entusiasmo às propostas de trabalho, colaborando não só com o empenho como com úteis sugestões e críticas, apesar dos naturais temores iniciais pela diferença das rotinas de cursos presenciais e pela inclusão de mídia digital.

A pesquisa e todas as ações necessárias para seu desenvolvimento - leituras, discussões, reflexões etc. - são parte do esforço de a universidade dar aos professores (discentes) não só um acervo de conhecimentos que lhes permitisse construir sua própria concepção de educação como, também, capacidade de melhorar o desempenho de seus alunos(as) e de fortalecer os vínculos com suas escolas.

No total, foram atendidos 2.400 alunos, distribuídos nos já mencionados sessenta grupos de quarenta, perfazendo um total de 12 circuitos - conjuntos de cinco turmas ligadas à rede intranet para efeito de audiência de video-aulas e outras interações que se fizeram necessárias. Essa configuração permitiu que, em determinadas ocasiões, todos os circuitos fossem conectados e interagissem entre si e com a coordenação central.

O público-alvo do Programa foi composto por professores concursados e em exercício na Educação Infantil e no $1^{\circ}$ Ciclo do Ensino Fundamental das redes municipais de ensino das seguintes cidades participantes: Assis, Bertioga, Cabreúva, Guapiara, Guarujá, Itaquaquecetuba, Mongaguá, Osasco, São Bernardo do Campo, São Paulo e São Sebastião, todos situados no Estado de São Paulo, nos seguintes pólos: Assis, Artur Alvim (Leste 4), Bertioga, Butantã (Centro Oeste), Carapicuíba, Casa Verde (Centro), Itapeva, Itaquaquecetuba, Itu, Mauá, Mogi das Cruzes, Osasco, Parque Cecap (Guarulhos Norte), Penha (Leste 1), Santo André, Santos, São Bernardo, São Miguel Paulista (Leste 2), São Sebastião, São Vicente, Taboão da Serra, Tatuapé (Leste 5), Vila Galvão (Guarulhos Sul) e São Paulo.

Para o pleno desenvolvimento do PEC-USP criou-se um circuito de ambientes de aprendizagem com características especiais, tendo algumas unidades escolares da rede estadual sido escolhidas para abrigar essa infra-estrutura. A universidade, por sua vez, encontrava-se equipada com salas de geração de videoconferência, na forma de três pequenos estúdios com equipamento de videoconferência, um televisor de 29', câmera documental, videocassete, computador multimídia e sistema de som.

O programa incluiu cinco modalidades de atividades que, articuladas entre si, dão consistência à proposta pedagógica. A seguir cada uma delas:

. Videoconferência (VC) e Teleconferências (TC), que forneceram o suporte teóricoconceitual, por meio de aulas, palestras e dinâmicas de trabalho presencial virtual. Antecedendo e/ou sucedendo a estas formas de interação com docentes e convidados ocorreram os momentos de trabalho monitorado (TM), por meio de três tipos de sessões: on-line (ligadas à intranet), off-line (orientadas por um tutor) e de suporte. Tais procedimentos foram complementares às modalidades que seguem;

. Vivências Educadoras (VE): atividades complementares diretamente relacionadas a módulos, temas ou conteúdos do curso, que ocorreram sob a supervisão dos tutores e/ou orientadores, com carga horária variada; 
. Oficinas Culturais (OC): ocorreram sob a supervisão dos tutores e/ou orientadores, com carga horária variada;

. Escrita de memórias: atividades complementares que ocorreram sob a supervisão dos tutores e orientadores, com previsão de reuniões periódicas no decorrer do curso;

. Desenvolvimento de pesquisa e escrita de monografia - Trabalho de Conclusão do Curso (TCC): atividades que percorreram todo o programa, sob a supervisão dos orientadores acadêmicos indicados pela universidade.

\section{A avaliação do PEC na perspectiva dos professores}

A pesquisa de avaliação teve por objetivo verificar e analisar a extensão dos conhecimentos e atitudes gerados pelo PEC-USP (2003-2004) e sua influência nas práticas cotidianas dos profissionais.

Os resultados obtidos permitem avaliar o programa em questão e fornecem subsídios não só para o aperfeiçoamento de cursos com as mesmas características como, também, para cursos de formação de professores em geral. Tais dados empíricos são necessários para embasar decisões dos responsáveis pelo planejamento, pela execução e avaliação dos currículos de cursos de preparação de docentes de acordo com a legislação em vigor e que se propõem a ter efeito positivo na educação escolar.

Em recente pesquisa analisando a forte relação entre a experiência do professor e o aproveitamento dos alunos, Levine (2006, p. 36) sugere que "temos a capacidade de aumentar a eficácia de nossos docentes aumentando a retenção e rendimento de professores experientes".

Considera-se essencial que os programas de formação de educadores forneçam elementos para o aperfeiçoamento dos pesquisadores responsáveis por políticas educacionais, gestores de instituições escolares e, principalmente, professores, não se encerrando sem propostas para outras situações do sistema educacional.

\section{Metodologia}

Tendo em vista as questões que se decidiu investigar, o número de participantes do curso e sua dispersão em 24 municípios, optou-se por estruturar um questionário com vinte questões com graduação de cinco pontos entre o máximo e o mínimo, em escala decrescente. Os instrumentos foram enviados por correio, acompanhados de envelopes para facilitar a devolução das respostas. Para que os signatários respondessem de forma isenta e livre de influências que pudessem afetar suas opiniões, a pesquisa foi feita aproximadamente três meses após o término das atividades regulares.

A elaboração e escolha do formato do questionário respeitou a tradição do curso, bem familiar aos alunos. As decisões sobre o número de questões e as alternativas para cada uma delas foram objeto de cuidadoso trabalho da equipe coordenadora, assessorada por especialistas da FUVEST (Fundação Universitária para o Vestibular), que participaram na elaboração e no processamento do material.

Do referido instrumento fazia parte uma carta endereçada aos alunos explicitando a 
motivação da busca de informações. Ainda na parte frontal do documento constava um espaço para que, livremente, fossem feitos comentários, avaliações e sugestões. No verso dessa folha propunha-se um questionário com vinte questões fechadas.

Foram postadas 1.863 cartas e devolvidas 703 (37,7\%), das quais, por várias razões, 148 não puderam ser processadas. Os resultados, portanto, referem-se a $655(35 \%)$ dos questionários. $\mathrm{O}$ interesse pela pesquisa pode ser ilustrado pela seguinte informação dada pela mãe de uma aluna: "Ela (a aluna) respondeu por telefone. Ela está fora do Brasil, mas está na ativa. Dá aula no Japão, disse que aproveitou bem o curso e que vale a pena. Fará outro, se possível".

As respostas livres revelam aspectos e opiniões não abarcadas pelo questionário, ampliando consideravelmente o alcance da pesquisa.

\section{Resultados}

Apesar da conexão entre as vinte questões, os resultados das perguntas, para efeito da análise, foram agrupados em cinco categorias que reúnem e se referem a aspectos específicos da investigação e que refletem as relações:

\section{A - Impacto do curso}

1) $\mathrm{O}$ curso de PEC-USP foi (escala em $\%$ ):

ótimo $64,6 \%-29,5 \%-5,7 \%-0,1 \%-0 \%$ péssimo.

2) Repercussão do curso na unidade escolar: total $42 \%-37,5 \%-17,3 \%-2,8 \%-0,5 \%$ nula.

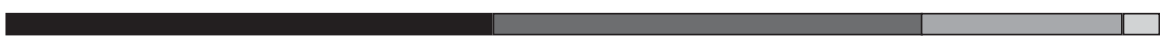

\section{B - Formação profissional}

3) Após o curso você alterou sua prática docente: totalmente $36,6 \%-43,7 \%-16,8 \%-2,2 \%-0,8 \%$ nada.

4) O curso estimulou sua participação em atividades de aperfeiçoamento: totalmente $55,5 \%-29,6 \%-11,5 \%-2,2 \%-1,2 \%$ nada.

5) $\mathrm{O}$ curso estimulou sua participação em atividades de extensão: totalmente $45,6 \%-32,1 \%-16,6 \%-4,2 \%-1,6 \%$ nada. 
Krasilchik, M.; Nicolau, M. L. M.; Cury, M. C.

6) Mudanças profissionais após o curso: positiva $57,2 \%-26,2 \%-12,9 \%-2,2 \%-1,5 \%$ negativa.

7) Mudanças pessoais após o curso: positiva $62 \%-24,2 \%-11,8 \%-1,4 \%-0,6 \%$ negativa.

\section{C - Mudanças nas atividades escolares}

8) Mudanças nas atividades escolares: positiva $54,5 \%-30,7 \%-12,5 \%-2 \%-0,3 \%$ negativa.

9) Mudança na seleção de conteúdos das suas aulas: positiva $56 \%-30,1 \%-11 \%-2,5 \%-0,5 \%$ negativa.

10) Mudanças nas atividades práticas das suas aulas: positiva $54,6 \%-30,5 \%-12,1 \%-2,5-0,3 \%$ negativa.

\section{D - Mudanças de relacionamento nos vários níveis da escola}

11) Mudanças nas relações com seus alunos: positiva $58,8 \%-25,3 \%-13 \%-2,5 \%-0,5 \%$ negativa.

12) Mudanças nas relações com seus colegas: positiva $51,6 \%-27,7 \%-16,8 \%-2,3 \%-1,5 \%$ negativa.

13) Mudança nas relações com a direção da escola: positiva $44 \%-28,9 \%-21,2 \%-3,8 \%-2 \%$ negativa.

14) Mudanças nas relações com a coordenação da escola: positiva $45,3 \%-28,4 \%-20,6 \%-3,5 \%-2,2 \%$ negativa. 
15) Mudanças nas relações com os funcionários da escola: positiva $48,3 \%-25,5 \%-21,2 \%-3,1 \%-2 \%$ negativa.

16) Mudanças nas relações com as famílias dos alunos: positiva $50,9 \%-28,8 \%-16,6 \%-2,5 \%-1,2 \%$ negativa.

\section{E - Reflexões e ações promovidas pelo curso}

17) O curso promoveu ações de inclusão social: totalmente $47,7 \%-32,6 \%-14,3 \%-3,4 \%-2 \%$ nada.

18) O curso promoveu reflexões sobre questões éticas: totalmente $64,7 \%-27,5 \%-6,1 \%-1,5 \%-0,2 \%$ nada.

19) O curso promoveu reflexões sobre ações ambientais: totalmente $51,6 \%-34,4 \%-11 \%-2,6 \%-0,5 \%$ nada.

20) O curso promoveu reflexões sobre políticas educacionais: totalmente $62,4 \%-28,4 \%-8 \%-1,2 \%-0 \%$ nada.

\section{Discussão}

Como programas de educação continuada em serviço tendem a aumentar, cresce também a necessidade de coletas de informação e pesquisas como as descritas no sentido de subsidiar a organização e implementação de tais programas e outros, de formação de professores. $\mathrm{O}$ ângulo de análise adotado foi aproximado do que é apresentado como ecológico e orgânico, propondo uma mudança no desempenho dos docentes no âmago da escola em resposta à questão: "O que ocorre na sala de aula e que ecologia educacional é necessária para apóia-la?” (STEWARD e JOHANEK, 1998, p. 147).

Essa decisão norteou a elaboração e análise do instrumento, tendo-se baseado na convicção de que propostas curriculares elaboradas levando em conta apenas objetivos e conteúdos tendem a esgotar-se em si mesmas por desconsiderar que as escolas e a universidade são sistemas dinâmicos com diferentes expectativas, fluxo próprio de idéias, demandas e decisões que influem poderosamente nas atividades dos docentes. A diferença cultural entre a universidade e as escolas exige mutualismo para a evolução de novos arranjos organizacionais. 
Ainda de acordo com Steward e Johanek (1998), a conexão universidade-escola ocorre em três âmbitos de ação que interagem: nível da prática, nível da cultura institucional e nível das relações externas. Os resultados deste trabalho indicam a importância de cada uma dessas áreas e de sua interação.

Os professores-alunos do PEC têm responsabilidades de ensinar bem em suas classes, de promover e monitorar seu próprio aperfeiçoamento intelectual, emocional e profissional, liderar um processo de mudança e melhorar o funcionamento do sistema educacional.

No exame dos questionários na categoria $\mathrm{A}$, em que as perguntas incidem sobre o curso, de forma geral, verifica-se a maior pontuação de apoio ao trabalho $(64,6 \%)$. Na Unidade Escolar, uma menor repercussão é significativa (42\%), o que é corroborado pelas respostas às questões da categoria 4 , relativas às relações com a direção e coordenação da escola. Há várias possíveis interpretações para esse dado: resistência da direção e de colegas, dificuldades materiais para execução das atividades, desinteresse do sistema para propostas inovadoras, entre outras.

Quando passou-se a considerar o impacto nas atividades profissionais - categoria B - foram encontradas as menores pontuações de todo o questionário para alteração na prática docente: a única das vinte perguntas em que $43 \%$ admitem que não houve mudança total. É interessante a resposta livre de uma professora, que explica que não mudou muito porque ela já fazia o que o curso recomendava: "muito do que foi colocado no PEC já vinha aplicando no men diaa-dia, mas é essencial retomarmos para melhorar nossa prática, pois o comodismo não nos leva a refletir. As questões de ética e os conteúdos especificos foram o que mais me fizeram refletir".

A influência do professor no complexo ambiental onde ocorrem as atividades do PEC depende de sua capacidade de regular a construção de reações individuais e coletivas, a classe e em conseqüência os conhecimentos, habilidades e posturas das crianças. A sua capacidade de deliberação leva em conta as demandas fundamentais contidas nas modalidades de aprendizagem adotada e as limitações impostas pelo ambiente imediato e mais externo. (RUÉ, 2003, p. 132)

A repercussão nas tentativas de mudanças na atuação dos docentes foi positiva e estimulou maior envolvimento em atividade de aperfeiçoamento. A categoria C, que engloba itens referentes às variações de postura nas atividades escolares para melhoria do ensino, objetivo maior do curso, manteve um patamar constante de cerca de $55 \%$, o que, de alguma forma, contradiz o item 3 já analisado, referente à mudança na prática docente. É possível supor que, como iniciativa individual nas aulas, o professor consegue fazer transformações aplicando o que aprendeu no curso, como revela uma aluna. "O curso foi muito importante na minha prática pedagógica, aprendi muita coisa boa, que pratiquei no meu dia-a-dia de trabalbo... mudou muito a minha vida".

Passando a analisar os relacionamentos nas escolas - categoria D - foi constatada mudança amplamente positiva no que se refere às relações entre alunos e colegas.. No entanto, as relações positivas com administração e direção da escola são menores do que as indicadas com funcionários e familiares dos alunos. Isso parece sinalizar as dificuldades de compreensão 
- ou desinteresse das propostas - de docentes pelas instâncias decisórias e preponderância com preocupações administrativas.

É interessante analisar aquelas ações promovidas pelo curso - categoria E -, voltadas para as atividades de extensão e ações de inclusão social. As preocupações com a política educacional predominam, alcançando uma das mais altas pontuações. Trata-se, pois, de questões éticas que os professores têm que enfrentar em seu trabalho diário na classe. $\mathrm{O}$ processo de envolver membros da comunidade onde a escola é situada produz uma colaboração que beneficia mutuamente estudantes e professores.

Os projetos de extensão, que geralmente implicam em relações com a comunidade, tiveram uma pontuação menor possivelmente pela sobrecarga de trabalho, que exigem também intenso esforço coletivo.

Os problemas ambientais preocupam os professores. Para além das situações relativas à preservação, restauração ou modificação do ambiente (tão presente na atualidade), os apelos do curso parecem ter-lhes suscitado novas inquietações. A presença constante de temas como questões de energia, suprimento de água, poluição, entre outros, nas comunidades e na mídia, muitas vezes com opiniões controvertidas e dependendo de interesses muito diversos, exigiu dos professores capacidade de análise rigorosa e inserção na apresentação aos estudantes, evitando imposição de suas opiniões pessoais.

As sugestões apresentadas nessa categoria apontam para a necessidade de aprofundar assuntos referentes à inclusão de alunos deficientes visuais, auditivos, de educação de jovens e adultos e legislação educacional.

\section{Conclusões}

As respostas obtidas indicam que o curso foi bem sucedido e permitem traçar diretrizes para ações futuras. No nível da coordenação do Programa, há projetos e interesse por atividades de formação continuada que dependem de políticas públicas executadas por diferentes instâncias das secretarias de educação e das universidades.

Dois grandes grupos de demandas preponderaram: cursos de complementação para habilitar os professores em funções de supervisão e coordenação; e cursos de pós-graduação, de caráter mais acadêmico. Tais pedidos revelam que foi possível despertar interesse por aprofundamento e ampliação de expectativas profissionais e acadêmicas, essenciais para projetos de educação continuada.

Embora o material impresso tenha sido muito bem avaliado pela maioria, um dos raros aspectos negativos apontados foi "a densidade dos textos e o tempo insuficiente para a realização dos estágios e trabalhos". A respeito do trabalho de tutores, orientadores e assistentes foram feitos escassos comentários pontuais sobre o desempenho individual de alguns deles, indicando certos problemas de personalidade.

Os resultados da pesquisa denotam, também, que a orientação acadêmica associada à experiência possibilita uma intersecção teoria e prática dos docentes em seus locais de trabalho, bem como melhora sua auto-estima. Declarações de professores no questionário ilustram de forma marcante essa afirmação: 
Krasilchik, M.; Nicolau, M. L. M.; Cury, M. C.

"O PEC foi um marco de novas idéias e mudanças na minha vida profissional e pessoal";

"O curso me fez, me tornar mais segura nos argumentos, crítica e reflexiva nas minhas ações e na unidade escolar";

'O curso fornecen um repertório para todos os professores que acreditam e querem ser 'educador' envolvido na aprendizagem de seus alunos";

"[...] fez. com que eu procurasse me informar mais, ou seja, fiquei com vontade de saber mais e mais";

"Todos os professores, mesmo aqueles que já possuem babilitação em educação de/ em nivel superior deveriam ter a oportunidade de participar de um curso tão completo como esse";

"O curso forneceu um repertório para todos os professores que acreditam e querem ser 'educador' envolvido na aprendizagem de seus alunos".

A profissão docente é confrontada atualmente em problematizações que se ampliam, provocando desencontros, desassossegos e muitas indagações aos protagonistas desse processo: "mudar de quê e para quê?; qual a minha prática atual?; que conceitos são expressos na minha prática?; como posso mudar?".

Parece que no conceito de mudança das propostas de reformas educacionais estão implícitas considerações a respeito do valor que têm as práticas educativas habituais e cotidianas dos professores. É lícito dizer que os processos de mudança sempre afetam o âmago das pessoas, como defende o conceito de Teorias Implícitas ou Subjectivas ${ }^{4}$, que ganha terreno na investigação sobre pensamentos do professor (GARCÍA, 1999).

Fullan e Hargreaves (2000) apontam nessa direção quando estabelecem que qualquer inovação implica, inevitavelmente, utilização de materiais curriculares diferentes dos habitualmente usados e, como conseqüência, pode ocorrer uma mudança maior ou menor na prática de ensino dos/as professores/as, em suas competências, condutas, estilos pessoais, assim como uma modificação de suas crenças ou concepções educativas.

A complexidade de um curso com midias interativas inclui os alunos desses cursos em um processo de revolução cultural e social, um dos aspectos marcantes de uma nova educação inclusiva que pode diminuir disparidades educacionais. (PENIN, 2006, p. 5)

\footnotetext{
${ }^{4}$ Considera-se o professor um "sujeito epistemológico", capaz de gerar e contrastar teorias sobre sua própria prática (GARCIA, 1999, p. 47).
} 
Acreditamos que devemos aproveitar a necessidade criada de educação continuada para contribuir, efetivamente, para o aperfeiçoamento dos professores e, conseqüentemente, para melhorar seu desempenho nas escolas. As observações dos docentes acerca do impacto do curso parecem reforçar tal afirmação:

"o PEC garantiu para a rede a possibilidade de seus professores terem a oportunidade de rever seus projetos e repensar suas dificuldades; as mudanças, talvez pelo curto espaço de tempo, não foram tão grandes, mas sem dúvida estão ocorrendo e todas têm sido bem positivas; o curso forneceu um repertório para todos os professores que acreditam e querem ser 'educador' envolvido na aprendizagem de seus alunos".

Os professores participantes das várias fases do projeto passam "por um radical processo de revisão de sua concepção e expectativas do curso" que foi recebido no início com desconfiança e perplexidade, mas que ao longo das atividades foi surpreendentemente fácil. (KRASILCHIK, 2006, p. 23)

Outro aspecto importante para tornar o ensino atraente e adequado às necessidades dos alunos é a presença daquelas ações que têm a preocupação de melhorar a cooperação entre diretores, coordenadores, gestores de forma geral e professores em benefício da escola.

A importância atribuída aos temas ambientais, sociais e éticos parece indicar a responsabilidade e o comprometimento dos docentes com a busca de mudanças exigidas pela educação escolar no mundo contemporâneo e, em especial, no Brasil.

Programas como o descrito têm muito a oferecer como subsídio para ações que ampliem oportunidades para uma imensa população de professores, com a criação de novos ambientes e organizações curriculares adequadas a sua experiência e condições de trabalho. 
Krasilchik, M.; Nicolau, M. L. M.; Cury, M. C.

\section{Referências}

BRASIL. Lei no 9.394, de 20 de dezembro de 1996. Estabelece as diretrizes e bases da educação nacional. Lex: coletânea de legislação e jurisprudência, São Paulo, v. 60, n. 2, p. 3719-3739, 1996.

BRASIL. Ministério da Educação e do Desporto. Secretaria de Educação Fundamental. Diretrizes curriculares nacionais para o Ensino Médio: versão final. [Brasília, DF]: [s.n]. 1998.

FULLAN, M.; HARGREAVES, A. A escola como organização aprendente: buscando uma educação de qualidade. Porto Alegre: ARTMED, 2000.

GARCÍA, C. M. Formação de profesores: para uma mudança educativa. Porto: Porto Editora, 1999.

KRASILCHIK, M. Uma nova ecologia de aprendizagem. In: NICOLAU, M.; KRASILCHIK, M. (Eds.). Uma experiência de formação de professores na USP: PEC - Programa de Educação Continuada. São Paulo: Imprensa Oficial, 2006. p. 21-25.

LEVINE, A. Will universities maintain control of teacher education? Change, Washington, D.C., July-August, p. 36-43, 2006.

PENIN, S. Prefácio. In: NICOLAU, M.; KRASILCHIK, M. (Eds.). Uma experiência de formação de professores na USP: PEC - Programa de Educação Continuada. São Paulo: Imprensa Oficial, 2006. p. 1-5.

STEWARD, D.; JOHANEK, M. Enhanced academic connections. In: TIMPACE, P. M.; WHITE L. S. (Eds.). Higher education and school reform. California: Steward, 1998. p. $141-185$.

RUÉ, J. O que ensinar e por quê: elaboração e desenvolvimento de projetos de formação. São Paulo: Moderna, 2003.

Artigo recebido em fevereiro de 2007 e aprovado em julho de 2007. 